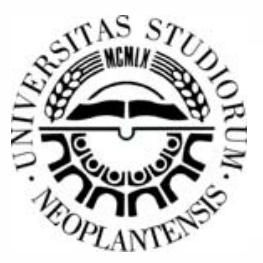

\title{
Hardfacing material solutions for high performance coatings in wear and corrosion applications
}

\author{
Frank Schreiber,* Benedikt Allebrodt, Tim Erpel \\ DURUM VERSCHLEISS-SCHUTZ GMBH, Willich, Carl-Friedrich Benz Str. 7, Willich, Germany
}

\begin{abstract}
The protection of machinery and structural components by thermal coatings is of huge economic importance. Each hour of downtime, caused by deficient coatings as a result of wear and corrosion, costs a fortune. Savings by reducing these downtime hours can be achieved by applying optimized functional coatings which show enhanced properties. The main welding processes for applying coatings are GMAW or OA, PTA or Laser, each with their pros and cons. The PTA process can be seen as the intermediate process bridging the low cost, high deposition rate and the expensive but high end Laser. Recently, the PTA and especially the laser process are gaining more attention and market shares. Nowadays the flux-cored wires can be upgraded more and more with for instance complex carbides and achieve coatings similar to the high performance coatings obtained by PTA and Laser welding but at much lower costs. The common problems accompanying the GMAW process: a large heat affected zone and dilution, can be circumvented by using the cold metal transfer (CMT), the AC-GMAW-and the GMAW hot wire process, allowing the flux-cored wires to fully deploy their large potential and compete with the welding techniques. The current paper will describe the modern GMAW hot wire process and then deal with innovative materials and process concepts for the high performance fluxcored wire to give a competitive alternative for the PTA process and expensive laser.
\end{abstract}

Key words: Thermal coatings; Flux-cored wire; GMAW-hot wire; Wear; Corrosion; Complex carbides.

\section{$1 \quad$ INIRODUCTION}

The application welding method examined in the scope of this paper is a combination of the classical GMAW welding plus additional in feed of a second flux-cored wire that is supplied as a hot wire with another current source. Only the in feed GMAW wire ignites a transferring electric arc in this, and the hot wire is subsequently guided hot into the still liquid melt by resistance heating. Basic advantages are provided by a very low thermal stress on the material supplied by hot wire in the range of the nickel-based alloys reinforced with tungsten carbide. Too-high thermal stress, e.g. by a transferred electric arc when welding, leads to disintegration of fused tungsten carbide FTC (W2C/WC) to tungsten monocarbide (WC) while emitting tungsten. The high hardness and high wear resistance of the FTC is reduced by this process [1]. At the same time, the dissolution of the carbides reduces the carbide size, which reduces the wear resistance of the coating [2].
The GMAW hot wire process was examined in terms of process characteristics and use of flux-cored wire diameters up to $2.4 \mathrm{~mm}$. Here, larger particles can be used in the FTC reinforced nickel-base alloys in addition to increase the content of FTC filler as well. For validation of these effects, also three other typical hardfacing alloys were examined. Here, the respective economical most relevant flux-cored wire alloys were chosen based on iron, nickel and cobalt [3][4].

\section{MATERIALS, MACHINES ANDEXAMNATION METHODSUSED}

The welding tests were conducted with the welding system DURWELD Alpha made by DURUM VERSCHLEISSSCHUTZ GmbH, equipped with two power sources from EWM AG. An EWM Alpha Q552 pulse was used as GMAW power source and an EWM TETRIX 552 as hot

* Corresponding author's.e-mail: aschreiber@durum.de 
wire power source. The principle and setup of welding technology is shown in Figure 1. S235 JR was used as base material for welding tests. The examined alloys are indicated in table 1

Table 1-Chemical composition of the flux-cored wire alloy types examined

\begin{tabular}{ccccccc}
\hline $\begin{array}{c}\text { Flux-cored } \\
\text { wire } \\
\text { DURMAT }^{\circledR}\end{array}$ & \multicolumn{6}{c}{ Main alloying additions in the used flux- } \\
\cline { 2 - 7 } cored wire (wt. \%) & C & Cr & B & W & + & Bal. \\
\hline FD61 & 5.2 & 22.0 & $<0.1$ & -- & Nb:7.0 & Fe \\
\hline $\begin{array}{c}\text { DUROLOY } \\
6\end{array}$ & 1.1 & 27.0 & -- & 4.5 & Fe: $<0.4$ & Co \\
\hline SE12/50 & 0.6 & 20.0 & 2.8 & 1.09 & $\begin{array}{c}\text { Si:4.9 } \\
\text { Mo:2.5 }\end{array}$ & Ni \\
\hline NIFD & $<0.1$ & $<5.0$ & $<2.0$ & -- & $\begin{array}{c}\text { FTC } \\
60 \%\end{array}$ & $\mathrm{Ni}$ \\
\hline
\end{tabular}

For experimental examination, four test materials were chosen to examine the procedure on different alloy base types. The materials here were chosen insofar as they had a high relevance for practice in addition to fundamentally different properties and applications of use:

- $\quad$ DURMAT ${ }^{\circledR}$ FD 61: Fe-based alloy with complex carbides for wear protection

- $\quad$ DUROLIT 6: Co-base alloy with eutectic precipitations

- $\quad$ DUROLOY SE 12/50: self-fluxing Ni-based alloy with good abrasion and corrosion resistance

- $\quad$ DURMAT ${ }^{\circledR}$ NIFD: Ni - based with FTC reinforcement for highest wear protection

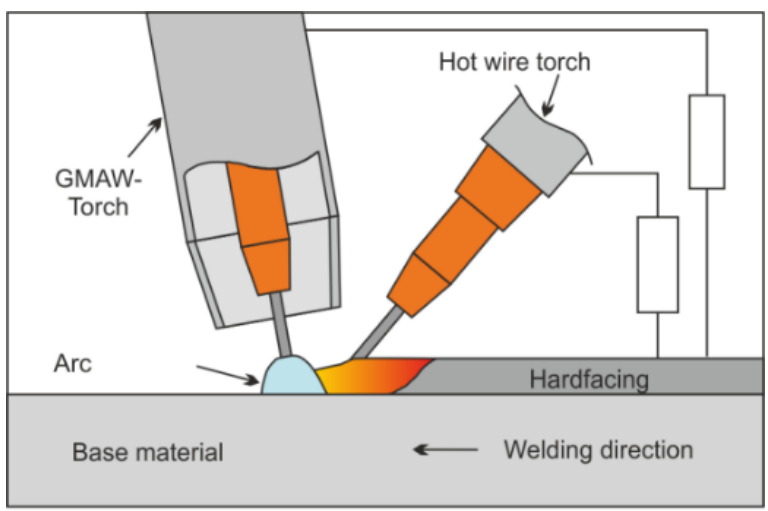

Fig. 1Schematic GMAW hot wire procedure

The focus of examination was on the FTC-reinforced nickel base alloy DURMAT ${ }^{\circledR}$ NIFD, which is the industrial standard at very high requirements. Furthermore, the highly chrome and carbon-containing iron-based alloy DURMAT ${ }^{\circledR}$ FD 61 was chosen in the area of the classical wear protection. DURMAT ${ }^{\circledR}$ NIFD as pseudo alloys with a matrix $f$ nickel and a high share of boron as well as large, embedded FTC particles offers a high degree of protection against abrasion and erosion. DURMAT ${ }^{\circledR}$ FD 61 offers a high content of primarily precipitated chrome and niobium carbides in eutectically reinforced austenitic matrix. The very high content of primary carbides and high hardness in excess of $65 \mathrm{HRC}$ offer good protection against abrasion and erosion as well. In addition, a nickel-based alloy and a cobalt-based alloy, which are also widely used, were examined for combined wear and corrosion resistance. The DUROLIT 6 alloy is used in many areas in which not only wear properties, but also good corrosion resistance and/or good high-temperature properties are required. This alloy type typically has a hardness of 40-43 HRC and can be used through the network of chrome and tungsten carbides eutectically distributed in a $\mathrm{CoCr}$ matrix at a usage temperature of up to $900{ }^{\circ} \mathrm{C}$, since it does not significantly reduce hardness across a large temperature range. DUROLOY SE 12/50 was chosen as a fourth alloy type that has high shares of chrome, silicone and boron, which gives it high corrosion resistance along with high hardness of approx. $50 \mathrm{HRC}$. This material is classically used to replace cobalt-based alloys.

The flux-cored wires used were made by DURUM VERSCHLEISS-SCHUTZ GMBH in Germany. The same flux-cored wire diameter and alloy type was used for GMAW and for hot wire process. The respective hot wires, however, were optimized successively for use as hot wire according to the results from the preceding examination.

\section{PROCESS ANALYSIS AND PROCESS OPTIMZATION}

Within the scope of this paper, the process behavior of the alloy DURMAT ${ }^{\circledR}$ NIFD was examined in detail. First, the behavior of the alloy in terms of energy introduction in conventional GMAW-welding was examined. For this, the welding voltage and wire feed rate were set at a wire diameter $1.2 \mathrm{~mm}$ and $2.4 \mathrm{~mm}$ so that different electric welding arc types formed. According to the information in literature, the arc type's short arc (KLB), transfer arc and spray arc were set [5]. Due to the low thermal stability of the hard phase FTC, which is very important for wear protection of this alloy, the hard phase content preserved completely as FTC was chosen as an evaluation criterion. Welding took place using stringer bead technique with a welding speed of $60 \mathrm{~cm} / \mathrm{min}$. Figure 2 shows the content of preserved FTC particles depending on the electric welding arc types used or the different welding voltages. It is clear that the increased energy input, e.g. in the arc types transitional arc and spray arc, clearly reduces the preserved FTC content. A considerable share of the WSC enclosed in the wire at the beginning is broken down into $\mathrm{WC}$ and carbon by the thermal effect of the electric arc during welding.

Therefore, it could be confirmed that the alloy type DURMAT ${ }^{\circledR}$ NIFD has much better layer properties when welding with lower voltages in the short electric arc. Large voltage ranges lead to clear carbide dissolution. Additionally, it is evident that the flux-cored wire diameter of $2.4 \mathrm{~mm}$ has an advantage concerning the remaining carbide share in all electric arc types due to using larger FTC particles. For the further examination, the GMAWwire was used in the short electric arc mode in the range of the FTC-reinforced nickel-based alloy DURMAT NIFD. The additional hot wire was supplied to the process as another step now. In this case, wires with diameters $1.2 \mathrm{~mm}$ 
and $2.4 \mathrm{~mm}$ were examined in accordance with the preceding GMAW welding tests in order to examine the influence of the different hard phase contents and hard phase sizes. Firstly, the influence of the welding speed in string bead technique on the resulting contents of intact FTC when using both flux-cored wire diameters was examined. Reduction of the section energy coincides with reduction of the thermal stress on the hard phases due to the heat discharge that is usually 3-dimensional in surface welding. The ratio between GMAW wire and hot wire was stipulated at 3:2 here and all other welding parameters were kept constant.

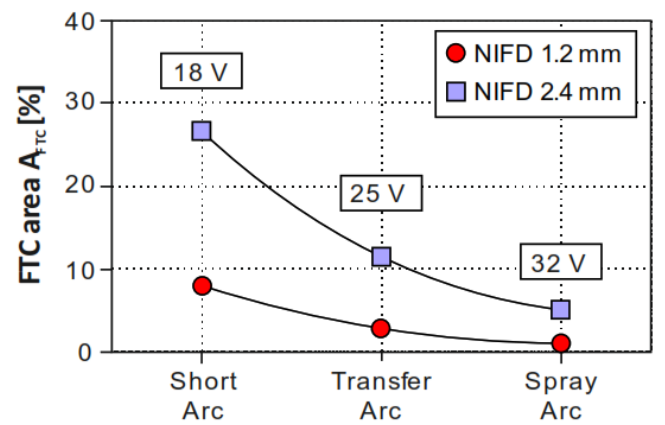

Fig.2 Interrelation between electric arc type and area percentage of the FTC share received

Evaluation of the area shares took place by ImageJ software in the cross-section. It could be shown here that the share of preserved FTC particles rises for both wire diameters as the welding speed increases and reaches a maximum at these parameters when a welding speed of 60 $\mathrm{cm} / \mathrm{min}$ is reached. Figure 3 shows the cross-section of DURMAT ${ }^{\circledR}$ NIFD with diameters of $1.2 \mathrm{~mm}$ and $2.4 \mathrm{~mm}$ of this test series with a welding speed of $60 \mathrm{~cm} / \mathrm{min}$. The cross-section shows that use of $1.2 \mathrm{~mm}$ wires leads to a highly homogeneous distribution of the carbides, but the carbides were dissolved slightly due to their low particle size.

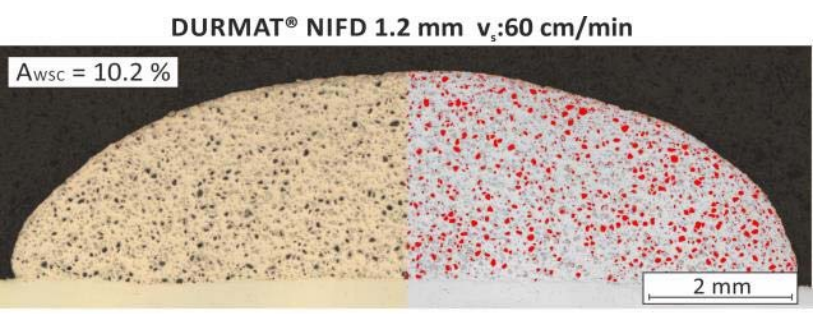

DURMAT ${ }^{\circledast}$ NIFD $2.4 \mathrm{~mm} \mathrm{v}_{\mathrm{s}}: 60 \mathrm{~cm} / \mathrm{min}$

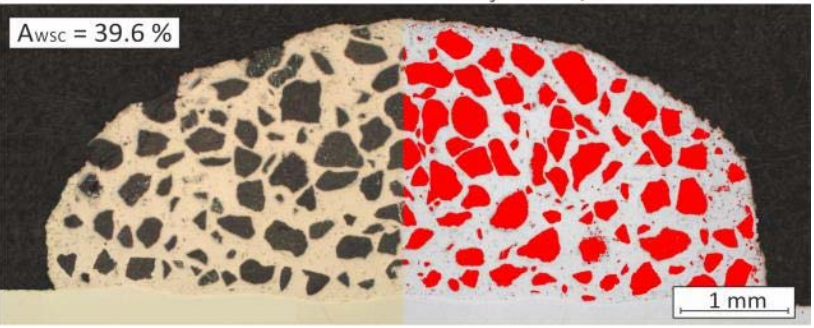

Fig. 3 Cross-section of GMAW hot wire hardfacing: welding speed $v s=60 \mathrm{~cm} / \mathrm{min}$

Nevertheless, completely intact FTC-particles will remain in the layer when using of an additional hot wire. The cross-section of the weld performed with $2.4 \mathrm{~mm}$ fluxcored wire diameter shows that a much higher content of FTC is completely preserved. The combination of much larger FTC particles with the hot wire method shows that the FTC particles can be preserved nearly entirely. On the one hand, this is because the share of WSC supplied by the hot wire cannot be overheated by the electric arc. On the other hand, however, the melt of the MIG/MAG wire is effectively cooled down by the supply of the hot wire. The interrelation between the welding speed and the area percentage of the completely preserved FTC is shown in Figure 4.

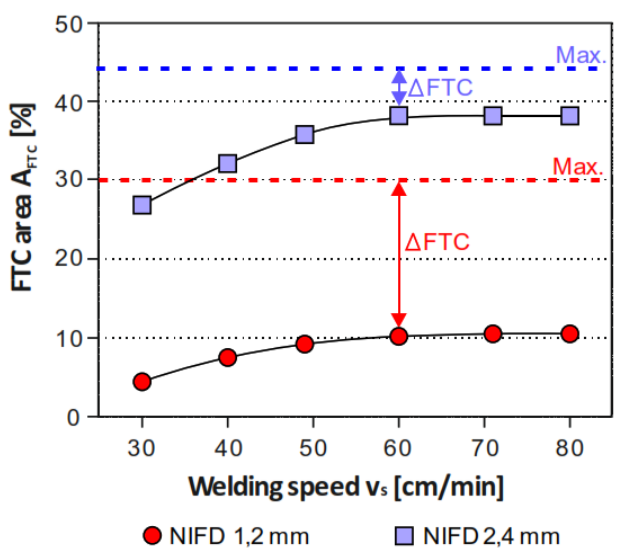

Fig. 4 Connection between welding speed vs and area percent of the FTC share received

Additionally, it becomes clear that use of larger FTC particles at a $2.4 \mathrm{~mm}$ flux-cored wire diameter achieves nearly the theoretical maximum of preserved FTC particles due to the low energy introduction to the hot wire. The difference $\triangle F T C$ between the theoretical maximum content and the content of intact FTC contained in the cross-section could be clearly reduced as compared to the $1.2 \mathrm{~mm}$ fluxcored wire and is shown in Figure 5.
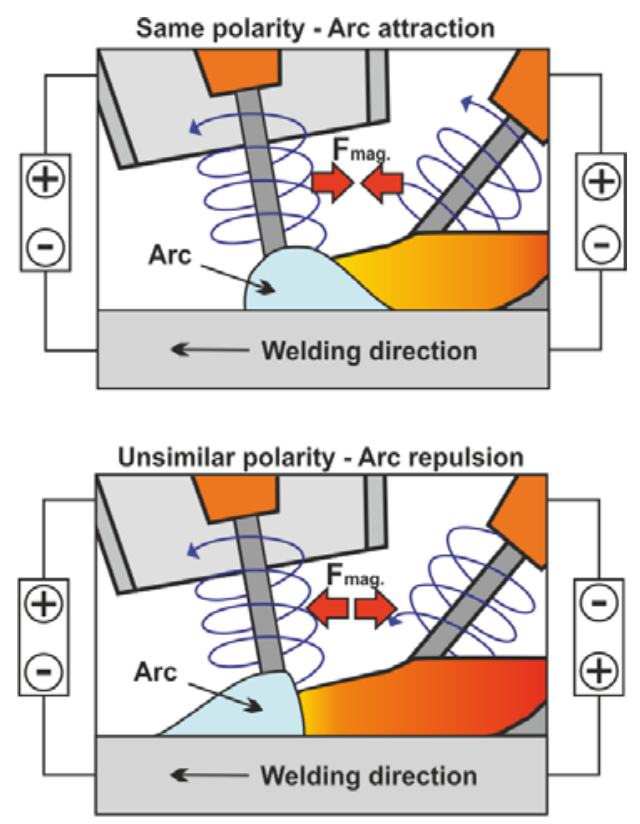

Fig. 5 Influence of the magnetic fields on the position of the electric arc in welding: different polarity 
It has also become clear that the magnetic field produced by the hot wire may impair process stability of the GMAW wire if the distance is too short, when the GMAW wire is welded in the short electric arc. Here, further tests are performed at the moment, which examine the influence of optimized characteristic curves for the short electric arc range and for the impulse electric arc range.

\section{METAШOGRAPHCRESULTS}

Use of the oscillating welding technique was examined in detail for practice examination of the alloys. Here, the slower welding speed directly increases the section energy, which usually leads to a slight to medium reduction of the FTC particles in the range of the nickel-based alloys with FTC reinforcement, though the influence of fluctuating process stability can be clearly minimized in this manner. For all alloy types, the influence of increasing addition of hot wire to the microstructure was examined systematically. Therefor feed rate, voltage and current of the GMAW wire have been kept constant while the feeding rate of the hot wire has been increased. Equally, the welding speed was increased at the same time in order to produce a comparable bead geometry. The further process parameters, such as free wire lengths, oscillation parameters, angles of attack, etc. were kept constant. It becomes clear that a small addition of hot wire already essentially influences the resulting layer structures. Thus, the addition of hot wire can clearly improve the distribution of FTC particles in the layer, and significantly increase the share of FTC particles received. It is equally visible that the FTC grain size used is nearly completely preserved due to the low thermal stress at the highest hot wire feed rate even at a high melting rate of $10.8 \mathrm{~kg} / \mathrm{h}$. For the alloy version DUROLIT 6, thermal stress of the wire filling is desired, in contrast to the FTC-containing nickel based alloys, in order to produce a homogeneous structure without defects and segregations. Since the technical properties of this alloy are primarily determined by the chemical composition, the mixture with the base material is decisive. It has become clear that a very low dilution of less than $10 \%$ can be reached with a 1-layer welding already, and that the hardness of pure welding material is already achieved. This could also be confirmed by the chemical composition at the surface. The 1-layer weld already completely achieved the technical properties of the alloy. The material DUROLOY $12 / 50$ was chosen as an alternative to cobalt-based alloys with a hardness of 48-52 HRC. Since this alloy is also primarily used when a combination of wear and corrosion protection is needed, we have examined the hardness, the chemical composition at the surface, and the dilution. The dilution was at a low value of $14.6 \%$. The alloy thus reached the required hardness with an average of $49.7 \mathrm{HRC}$ in the first layer already. To review the chemical composition, the samples were then polished at the surface and examined with a spark spectrometer (OES). The iron content, e.g., could be lowered by about factor 7 from $20.9 \%$ to $2.85 \%$ at the surface of the 1-layer weld as compared to the MIG welding. Within the scope of the examination, the alloy
DURMAT $^{\circledR}$ FD 61 was also welded by oscillation technique and examined, as is common when producing wear plates. First, it could be shown that the welding type Open Arc (OA), i.e. welding without inert gas with selfprotecting flux-cored wires, is possible with the OA hot wire method used in this case with high melting rates of approx. $9 \mathrm{~kg} / \mathrm{h}$. It becomes evident that the dilution of only $14.2 \%$ could achieve a Rockwell hardness of $69.2 \mathrm{HRC}$ in the first layer, while the melting rate was very high at the same time. Here, the hardness in the first layer was increased by $4.3 \mathrm{HRC}$ as compared to the open arc welding. Figure 6 shows the cross-sections with indication of the technically relevant parameters and layer properties of the DURMAT NIFD, DUROLIT 6, DUROLOY SE 12/50 and DURMAT $^{\circledR}$ FD 61 materials when using the GMAW/OA hot wire method.

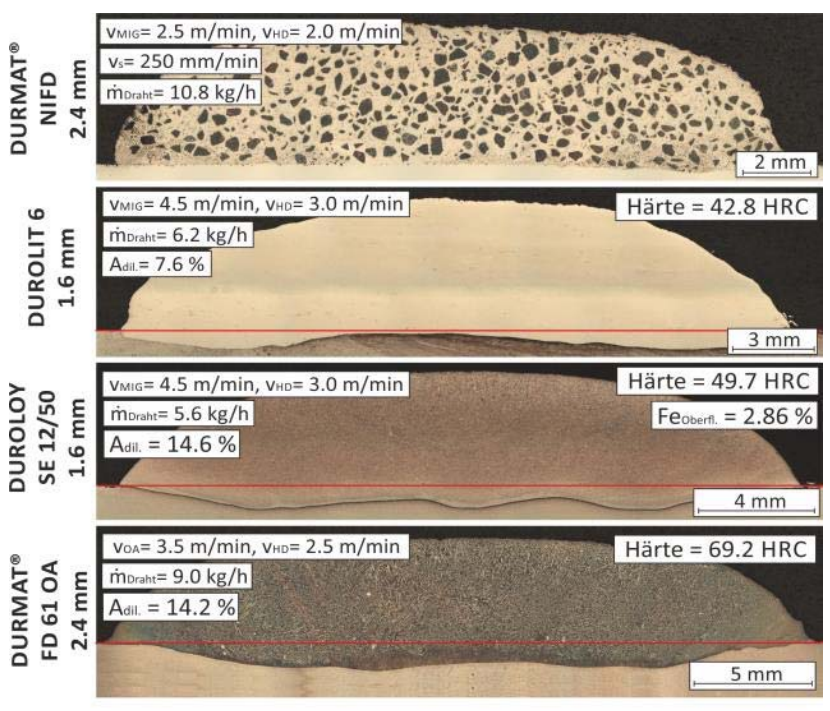

Fig. 6: Overview of GMAW hot wire hardfacings

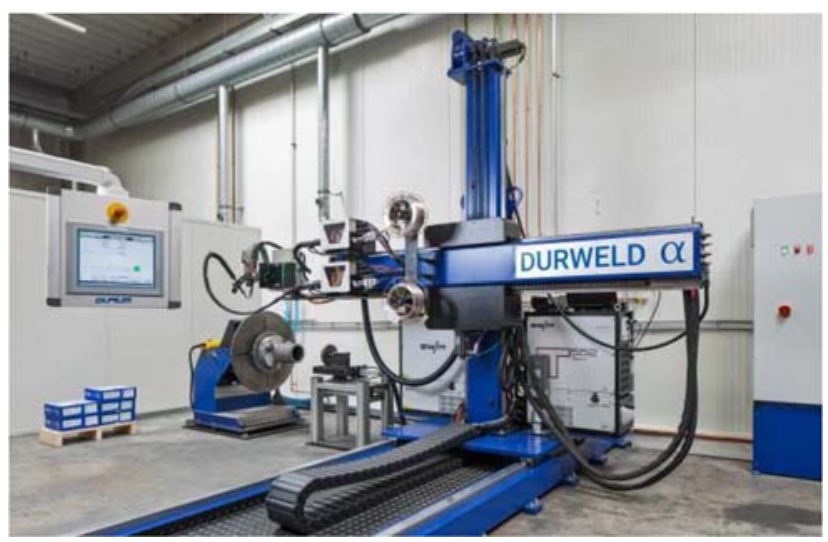

Fig. 7: Welding system DURWELD Alpha used with EWM current source techniques

\section{ApPUCATIONS}

The GMAW hot wire surface welding offers clear advantages for all examined alloy types concerning the layer properties and/or productivity. At the moment, transfer to practice is performed on several sample parts 
already, since the first preliminary tests using customer parts in the welding plant DURWELD Alpha led to promising results. The welding system is presented in Figure 7.

One possible area of application for the method in combination with the alloy DURMAT ${ }^{\circledR}$ NIFD is protection of the blade components or taper tap parts in open pit mining, Figure 8 . The highly wear-stressed areas required highest wear protection, since not only the less aggressive coal, but also regular overlay with many different compositions will be mined to expose the coal.

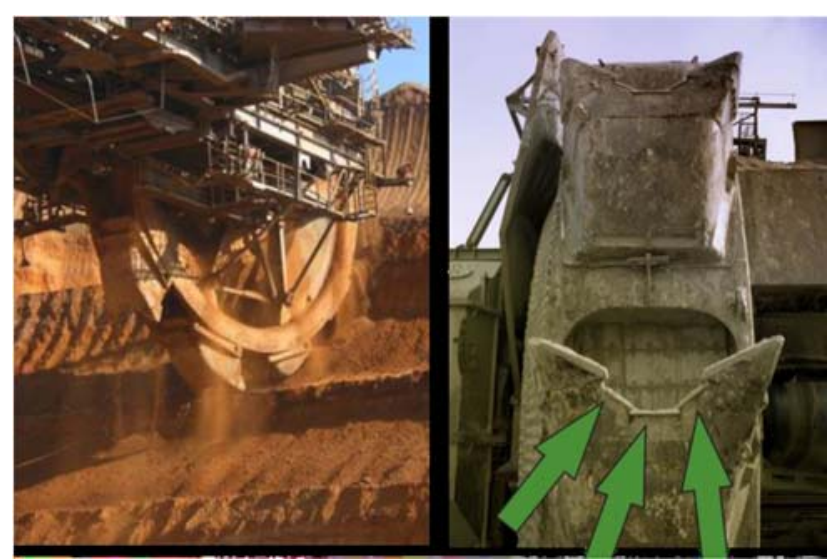

Fig. 8: Potential application: open-cast mining

\section{CONCLUSION ANDOUTLOOK}

Use of the GMAW hot-wire method can significantly increase the share of completely preserved FTC particles in the area of FTC-reinforced nickel-base alloys due to the reduced thermal stress on the filler material. It could be shown in the range of iron-, nickel- and cobalt-base alloys that use of the hot-wire technique reduced the respective dilution with base material and clearly improved the technical properties in single-layer application. Based on these results, further materials are being examined as well, since it can be assumed that at much larger number of materials can be processed with more beneficial properties than can be achieved in the conventional method when using the GMAW hot-wire method. Additionally, further adjustment of the power source's characteristic curves in the range of the short electric arc and pulse arc to the respective flux-cored wire types is currently underway in order to achieve optimally coordinated process conditions.

\section{REFERENCES}

[1.] Schreiber F. (2000) Wolfram-Schmelzkarbid im Verschleißschutz: Besonderheiten bei der schweißtechnischen Verarbeitung und Qualitätssicherung, 3. Fachtagung, Verschleißschutz von Bauteilen durch Auftragschweißen.

[2.] Uetz H. (1986). Abrasion und Erosion, Carl Hanser Verlag München Wien.

[3.] Knotek O., Lugscheider R., Eschnauer H.R. (1975). Hartlegierungen zum Verschleißschutz, Düsseldorf, Verlag Stahleisen

[4.] Berns H. 1998). Hartlegierungen und Hartverbundwerkstoffe, SpringerVerlag Berlin Heidelberg (

[5.] Dilthey U. (2006). Schweißtechnische Fertigungsverfahren 1, SpringerVerlag, Heidelberg 